\title{
3 Research Square

\section{Incidental Detection of Von Willebrand Disease: Can A Self-Assessment Anamnesis Questionnaire Protect From litigation And Minimize Complications?}

Ana Cristina Seabra Robalo Gomes Jorge ( $\sim$ ana.cristina.g.jorge@gmail.com )

University Hospital of Saarland https://orcid.org/0000-0002-1090-2337

\section{Arne Estler}

University Hospital Tübingen

Adelana Santos Stahl

CenterPlast Private Practice

Adrien Daigeler

BG Trauma Center Tübingen

Stéphane Stahl

CenterPlast Private Practice

\section{Case report}

Keywords: Risk management, self-assessment anamnesis questionnaire, litigation in surgery.

Posted Date: October 18th, 2021

DOl: https://doi.org/10.21203/rs.3.rs-955319/v1

License: (c) (1) This work is licensed under a Creative Commons Attribution 4.0 International License.

Read Full License 


\section{Abstract}

Introduction: Surgical specialties are often involved in legal actions associated with inadequate or incomplete documentation.

Case presentation: We report the case of a 22-year-old patient with gynecomastia who developed a unilateral hematoma after power-assisted liposuction and subcutaneous mastectomy performed in an outpatient setting under intercostal nerve block and monitored anaesthesia care. After revision surgery healing was uneventful. Further exams revealed a von Willebrand Disease. The patient had omitted a previous circumcision and the occurrence of a hematoma thereafter during the preoperative patient assessment. The specific and detailed anamnesis and the erroneous answer were documented on a structured self-assessment patient questionnaire for pre-surgical evaluation.

Conclusion: Literature suggests that standardized risk assessment improves the quality of the anamnesis, the patients' safety, the physician's time management. This case illustrates that it may also help defend the surgeons in case of medical litigation. However, physicians need to be aware of the risk of response bias.

Level of Evidence: Level V, case report

\section{Introduction}

Surgical specialties face a higher rate of malpractice suits than medical specialties. ${ }^{[1][2]}$ In today's litigious society, maintenance of high standards in daily practice with appropriate documentation of surgical risk factors is essential.

Consistent adherence to the surgical safety checklist of the World Health Organization (WHO) has been shown to considerably reduce the rate of postoperative complications, including the postoperative mortality rate. ${ }^{[3]}$ Likewise, the individual risk assessment using Caprini scores is of uttermost importance not only to improve patient safety but also to protect the surgeon from litigation. ${ }^{[4]}$

This case reports illustrates why self-assessment questionnaires are important for risk assessment and documentation. However, surgeons must be aware of the risk for recall bias and response bias, especially regarding sensitive or embarrassing medical information. ${ }^{[5][6]}$

\section{Case Report}

\section{Preoperative Evaluation}

We report the case of a 22-year-old male patient who presented in the outpatient aesthetic clinic due to gynecomastia. Days before the surgery, the patient filled out a self-assessment questionnaire in which he revealed having undergone an uneventful inguinal hernia surgery 4 years earlier. The past medical, family 
and drug histories were also unremarkable. The self-assessment questionnaire (Table 1) consisted of several strategically arranged questions with precise wording elaborated by a multidisciplinary team, in order to ensure a thorough evaluation of the patient's mental and physical health status. This carefully engineered questionnaire focuses on identifying the risk factors that are associated with surgical complications. A literature review of the most common complications and risk factors in breast surgery was performed and the results represented in Table 2. In addition the questionnaire assesses demographic and occupational data, as well as allergies and infectious diseases. The questionnaire allows patients to skip questions that are not applicable to their case, avoiding the deterioration of the quality of the provided information due to survey fatigue.

The patient was overweight (weight $91 \mathrm{~kg}$, height $178 \mathrm{~cm}$, body mass index (BMI) 28.7) and the physical examination revealed a bilateral symmetric primarily fibrous gynecomastia with minimal hypertrophy, without ptosis (grade I B according to Rohrich's classification ${ }^{[7]}$ ) (Fig. 1), but with cutis laxa, as well as striae cutis distensae in the breast upper quadrants. Likewise, laboratory studies showed no hormonal imbalances and the preoperative ultrasonography exhibited no pathologic findings.

\section{Operative Procedure}

Surgery was performed under conscious sedation with intercostal block with Ropivacaine $20 \mathrm{ml} 0.375 \%$ per side and the tumescent solution (Lidocaine $0.05 \%$, Adrenalin 1:1,000,000) was infiltrated into the subdermal layer along the preoperatively marked area. After a waiting period of 30 minutes, the liposuction of $75 \mathrm{~mL}$ from each breast was done with preservation of the superficial adipose layer to prevent any breast contour irregularities. Through a caudal periareolar incision, $38 \mathrm{~g}$ of the right and $35 \mathrm{~g}$ of the left glandular tissue and periareolar skin were resected. The nipple-areola complex was relocated to a more natural position, where the parasagittal line crossing the original position of the nipple meets the

fourth intercostal space. ${ }^{[8]}$ The surgery was uneventful and the patient was discharged 6 hours after the surgical procedure with minimal pain and unremarkable wounds without signs of hematoma.

\section{Postoperative Course and Revision}

On the evening of the same day, during the routine postoperative call, the patient expressed concerns due to a difference in size between both breasts. The clinical examination revealed a unilateral hematoma (Fig. 2) and the operative revision took place thirteen hours after the first surgery. Approximately $200 \mathrm{~mL}$ of hematoma were evacuated. An antibiotic prophylaxis was initiated postoperatively with Cefuroxime $500 \mathrm{mg}$ bid for 7 days. The drains were removed after 5 days and extracted a total of $120 \mathrm{~mL}$.

The patient omitted information about a circumcision done one year prior, which was complicated by postoperative bleeding up to 5 weeks after the procedure. After gynecomastia surgery, the patient was advised to do a hemostasiological evaluation, which revealed a von Willebrand disease (VWD) type 1. VWD is the hereditary bleeding disease with highest prevalence, affecting $1 \%$ of the population. ${ }^{[9]}$ 
Patients with type 1 VWD have a partial quantitative deficiency of von Willebrand factor and represent 70 to $80 \%$ of the cases. ${ }^{[9]}$ Our patient had a significantly reduced level of von Willebrand factor antigen and function of $48 \%$ and factor VIII of $48 \%$.

At the 10-week follow-up, the clinical examination exhibited a satisfactory wound healing (Fig. 3). If the patient had been truthful about the increased tendency to bleed in the self-assessment questionnaire the described complication could have been avoided.

\section{Discussion}

To our knowledge, this article is the first to present an anamnestic self-assessment questionnaire that aims at increasing the safety of surgical patients and to discuss the advantages of structured and standardized preoperative risk assessment.

The surgical complications described in the medical literature may not reflect their true incidence due to publication bias. ${ }^{[10]}$ Setting inaccurate standards for the medical professionals raises patients' expectations and, consequently, patients are more likely to file a malpractice lawsuit. Data from the Medical Professional Liability Association suggest that claims and the compensation payouts in plastic surgery are ever increasing. ${ }^{[11]}$ On the other hand, the analysis of published scientific literature and the review of malpractice lawsuits allow us to continuously improve patient care. ${ }^{[12]}$ Although the reported case did not result in litigation, it illustrates the added value for the assessment and documentation of surgical risk factors.

The intraoperative application of the widely accepted World Health Organization Surgical Safety Checklist (WHO SSC) reduced the mortality rate by $7 \%$ and inpatient complications about $4 \%$ within the first 30 postoperative days. ${ }^{[11]}$ In contrast to surgical safety checklists, including the WHO SSC, which were elaborated for the intraoperative period, ${ }^{[12]}$ the multidisciplinary Surgical Patient Safety System (SURPASS) is a surgical safety checklist that accompanies the surgical patient from the admission until the discharge. ${ }^{[12][13]}$ This checklist has been shown to prevent $29 \%$ of the cases that lead to irreversible disability and $40 \%$ of the events that resulted in death. ${ }^{[12]}$ The combination of both WHO SSC and SURPASS checklists may lead to a lower rate of complications during the hospital stay, urgent reintervention, and re-admissions. ${ }^{[13]}$

Nowadays, physicians struggle to provide the best patient care and involve patients in the decisionmaking process, while complying with the time constraints ${ }^{[14]}$ and the limited resources made available by the economy-driven society. ${ }^{[15]}$ However, meticulous patient anamnesis and preoperative evaluation helps tailor the treatment strategy to every patient. ${ }^{[16]}$

The reliability and accuracy of the anamnesis may be adversely impacted by various factors. Patients may reveal imprecise information either consciously, due to embarrassment, especially towards authority figures, such as doctors; or unconsciously, as the order and formulation of the questions may modulate 
the interpretation of the same. ${ }^{[17]}$ Besides, other elements affect the accuracy of the collected anamnestic information, for instance, age, educational level, and professional background. ${ }^{[16]}$

Written self-assessment questionnaires not only improve the efficiency of the physician's time, ${ }^{[18]}$ but also minimize the misreporting of anamnestic facts in comparison to a verbal patient interview. ${ }^{[17]}$ They have been shown to be a comprehensive and reliable tool to record the patients' anamnesis. ${ }^{[18]} \mathrm{A}$ study analyzed the effectiveness of a structured self-assessment questionnaire in a digitalized form ${ }^{[16]}$ and concluded that it can benefit both patients and medical professionals, improving the quality of the patients' records. ${ }^{[16]}$

A simply formulated, meticulous, and well-structured self-assessment questionnaire is a fundamental presurgical evaluation tool to minimize the risks involved in the surgical procedure and protect surgeons from malpractice lawsuits. Knowledge of the test-retest reliability and validity certainly adds to the quality of a clinical questionnaire but requires considerable time and effort and should not prevent the use of a systematic risk assessment questionnaire.

\section{Conclusion}

A good designed structured self-assessment questionnaire is a reliable and fundamental tool to evaluate patients before surgical procedures. They improve the patient safety and help protect surgeons from malpractice allegations.

\section{List Of Abbreviations}

VWD, von Willebrand disease. WHO SSC, World Health Organization Surgical Safety Checklist. SURPASS, Surgical Patient Safety System.

\section{Declarations}

\section{Ethics approval and consent to participate:}

Not applicable.

\section{Consent for publication:}

Written informed consent for publication of this article was obtained from the patient.

\section{Availability of data and materials:}

Not applicable.

\section{Competing interests:}

The authors declare that they have no competing interests. 


\section{Funding:}

The authors received no financial support.

\section{Authors' contributions:}

SS conceived the idea of the presented article. ACSRGJ and AE elaborated the literature research. ACSRGJ wrote the article. ASS, AD, and SS have been involved in revising the article critically for important intellectual content. All authors read and approved the final manuscript.

\section{Acknowledgements:}

We thank Prof. Dr. J. H. P. Hoffmeyer from the Leibniz Institute for the Social Sciences in Mannheim, Germany, for precious help with the elaboration of the preoperative self-assessment questionnaire.

\section{References}

1. Therattil PJ, Chung S, Sood A, Granick MS, Lee ES. "An Analysis of Malpractice Litigation and Expert Witnesses in Plastic Surgery," Eplasty. 2017 Sep 28;17:e30. PMID: 29062461; PMCID: PMC5638964.

2. Paik AM, Mady LJ, Sood A, Eloy JA, Lee ES. "A Look Inside the Courtroom: An Analysis of 292 Cosmetic Breast Surgery Medical Malpractice Cases," Aesthetic Surgery Journal. 2014 Jan 1;34(1):79-86. doi: 10.1177/1090820X13515702. PMID: 24396074.

3. Bergs J, Hellings J, Cleemput I, Zurel Ö, De Troyer V, Van Hiel M, Demeere JL, Claeys D, Vandijck D. "Systematic review and meta-analysis of the effect of the World Health Organization surgical safety checklist on postoperative complications," Br J Surg. 2014 Feb;101(3):150-8. doi: 10.1002/bjs.9381. PMID: 24469615.

4. Swanson E. "Caprini Scores, Risk Stratification, and Rivaroxaban in Plastic Surgery: Time to Reconsider Our Strategy," Plast Reconstr Surg Glob Open. 2016 Jun 13;4(6):e733. doi: 10.1097/GOX.0000000000000660. PMID: 27482481; PMCID: PMC4956845.

5. Vogel L. "Why do patients often lie to their doctors?," CMAJ. 2019 Jan 28;191(4):E115. doi: 10.1503/cmaj.109-5705. PMID: 30692114; PMCID: PMC6342698.

6. Choi BC, Pak AW. "A Catalog of Biases in Questionnaires," Prev Chronic Dis. 2005 Jan;2(1):A13. Epub 2004 Dec 15. PMID: 15670466; PMCID: PMC1323316.

7. Rohrich RJ, Ha RY, Kenkel JM, Adams WP Jr. "Classification and management of gynecomastia: defining the role of ultrasound-assisted liposuction," Plast Reconstr Surg. 2003 Feb;111(2):909-23; discussion 924-5. doi: 10.1097/01.PRS.0000042146.40379.25. PMID: 12560721.

8. Beer GM, Budi S, Seifert B, Morgenthaler W, Infanger M, Meyer VE. "Configuration and localization of the nipple-areola complex in men," Plast Reconstr Surg. 2001 Dec;108(7):1947-52; discussion 1953. doi: 10.1097/00006534-200112000-00015. PMID: 11743381.

9. Heijdra JM, Cnossen MH, Leebeek FWG. "Current and Emerging Options for the Management of Inherited von Willebrand Disease," Drugs. 2017 Sep;77(14):1531-1547. doi: 10.1007/s40265-0170793-2. PMID: 28791655; PMCID: PMC5585291. 
10. DeLong MR, Hughes DB, Blau JA, Hollenbeck ST. " Publication bias and the under-reporting of complications in the literature: have we dug our own pay-for-performance grave?," Plastic and Reconstructive Surgery. 2014, pp. 134(4S-1):24-43. doi: 10.1097/01.prs.0000455374.36401.cd

11. Boyd JB, Moon HK, Martin S, Mastrogiovanni DB. "Plastic Surgery and the Malpractice Industry," Plast.Reconstr. Surg. 2021, Jan 1;147(1):239-247. doi: 10.1097/PRS.0000000000007497. PMID: 33370072.

12. de Vries EN, Eikens-Jansen MP, Hamersma AM. "Prevention of Surgical Malpractice Claims by Use of a Surgical Safety Checklist," Ann Surg. 2011 Mar;253(3):624-8. doi:

10.1097/SLA.0b013e3182068880. PMID: 21209590.

13. Storesund A, Haugen AS, Flaatten H, Nortvedt MW, Eide GE, Boermeester MA, Sevdalis N, Tveiten $\emptyset$, Mahesparan R, Hjallen BM, Fevang JM, Størksen CH, Thornhill HF, Sjøen GH, Kolseth SM, Haaverstad R, Sandli OK, Søfteland E. "Clinical Efficacy of Combined Surgical Patient Safety System and the World Health Organization's Checklists in Surgery: A Nonrandomized Clinical Trial," JAMA Surg. 2020 Jul 1;155(7):562-570. doi: 10.1001/jamasurg.2020.0989. PMID: 32401293; PMCID: PMC7221852.

14. Konrad TR, Link CL, Shackelton RJ, Marceau LD, von dem Knesebeck O, Siegrist J, Arber S, Adams A, McKinlay JB. "It's about time: Physicians' perceptions of time constraints in primary care medical practice in three national healthcare systems," Med Care. 2010 Feb;48(2):95-100. doi:

10.1097/MLR.0b013e3181c12e6a. PMID: 20057331; PMCID: PMC3621071.

15. Vilmar K. "Der Arzt im Spannungsfeld zwischen Ethik und Kostendruck [Physicians caught between ethics and cost pressure]," Z. Evid. Fortbild. Qual. Gesundh.wesen (ZEFQ). 2009; 103(10):621-5; discussion 634. German. doi: 10.1016/j.zefq.2009.09.042. PMID: 20120189

16. Kopp M, Wetzl M, Geissler F, Roth JP, Wallner R, Hoefler D, Faby S, Allmendinger T, Amarteifio P, Wuest W, Cavallaro A, Uder M, May MS. "Structured Digital Self-Assessment of Patient Anamnesis Prior to Computed Tomography: Performance Evaluation and Added Value," Journal of Medical Systems. 2021 Jan 28;45(3):30. doi: 10.1007/s10916-020-01690-8. PMID: 33511485; PMCID: PMC7843739.

17. Redelmeier DA, Tu JV, Schull MJ, Ferris LE, Hux JE. "Problems for clinical judgement: 2. Obtaining a reliable past medical history," CMAJ. 2001 Mar 20;164(6):809-13. PMID: 11276550; PMCID: PMC80879.

18. Hershey CO, Grant BJ. "Controlled Trial of a Patient-Completed History Questionnaire: Effects on Quality of Documentation and Patient and Physician Satisfaction," American Journal of Medical Quality. 2002 Jul-Aug;17(4):126-35. doi: 10.1177/106286060201700402. PMID: 12153065.

\section{Tables}

Due to technical limitations, tables 1 and 2 are only available as a download in the Supplemental Files section.

\section{Figures}




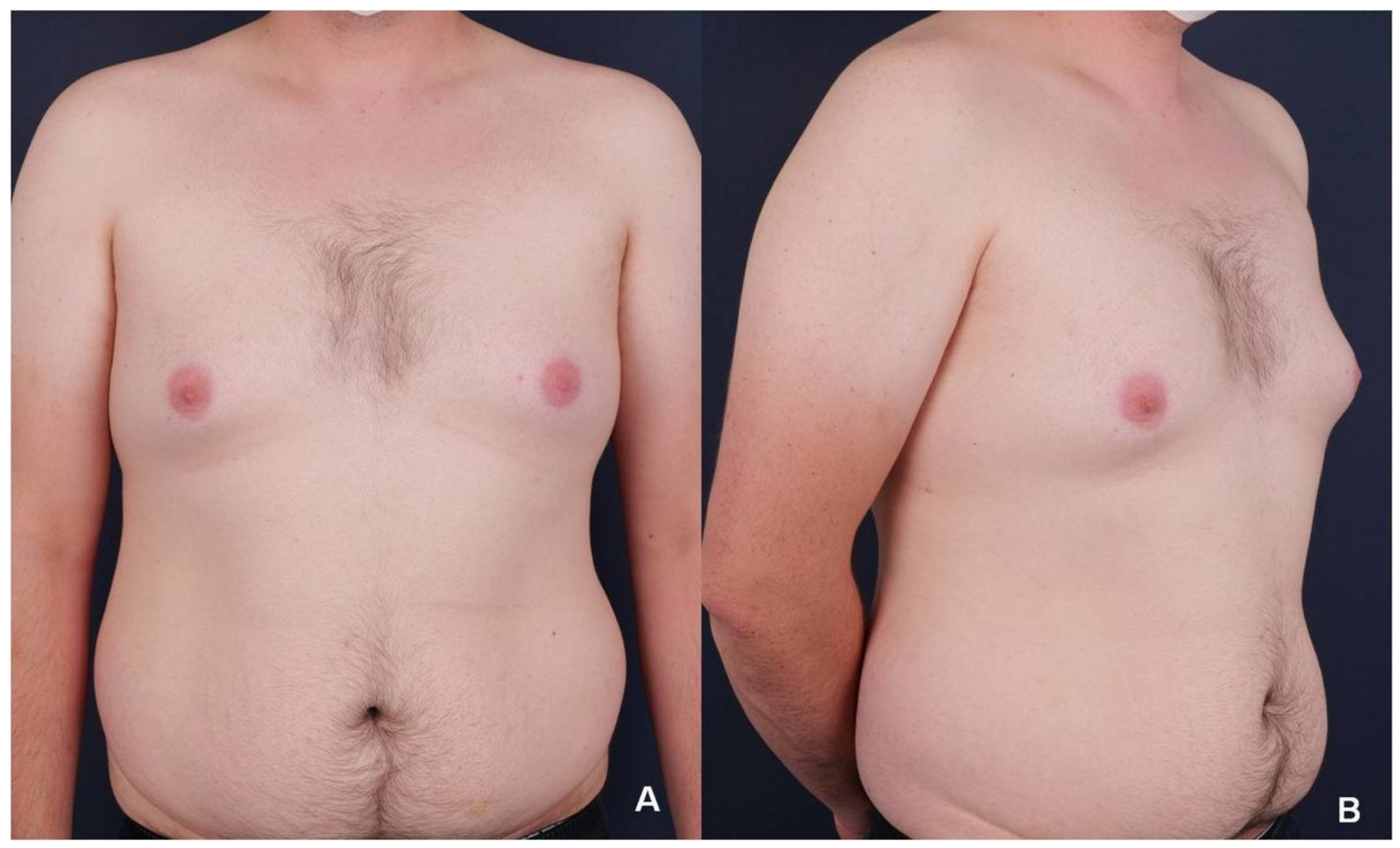

Figure 1

( $a$ and b): Twenty-two-year-old patient with bilateral symmetric gynecomastia grade I B according to Rohrich's classification. 


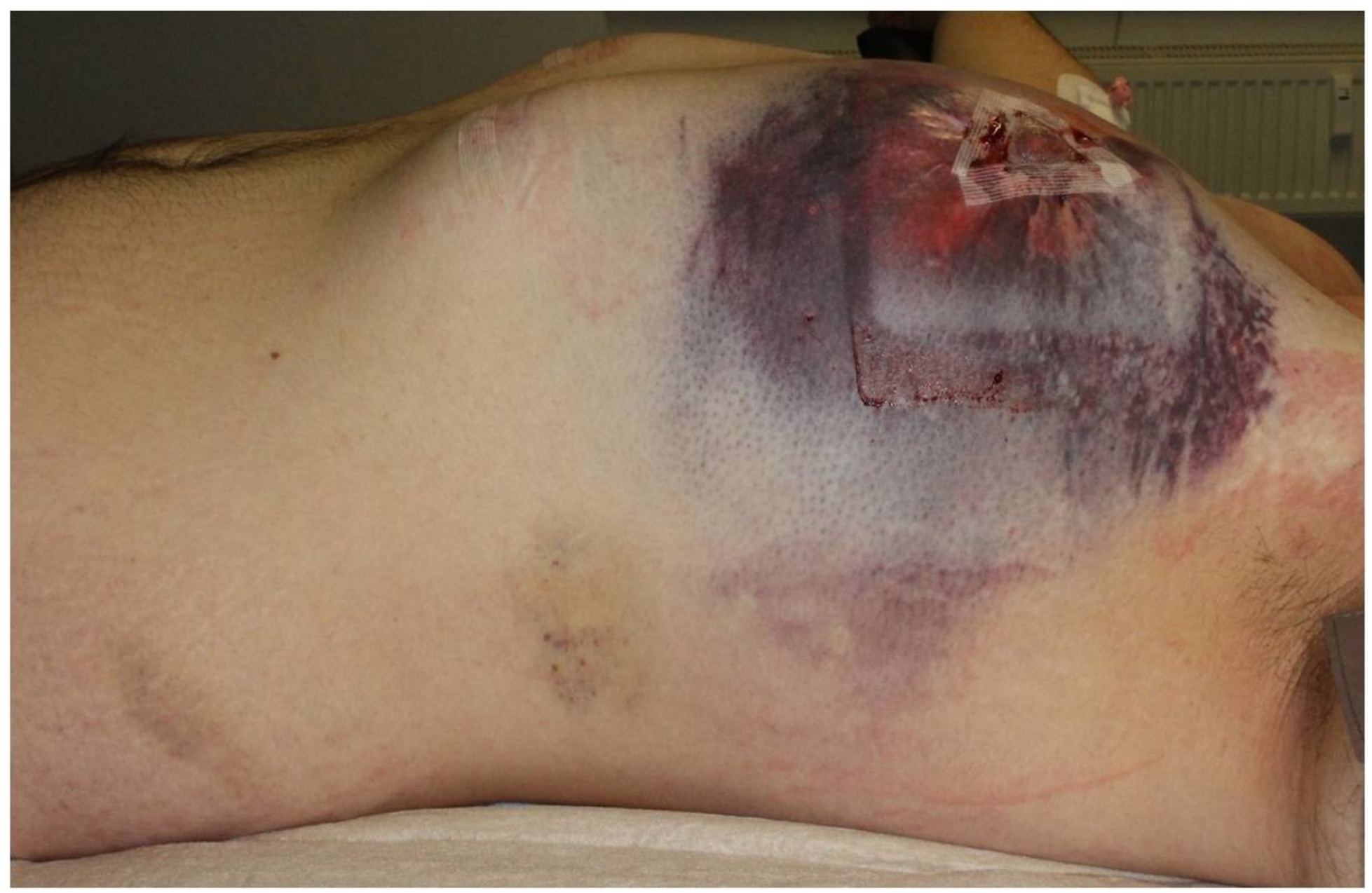

Figure 2

Unilateral hematoma thirteen hours after the power-assisted liposuction and subcutaneous mastectomy. 


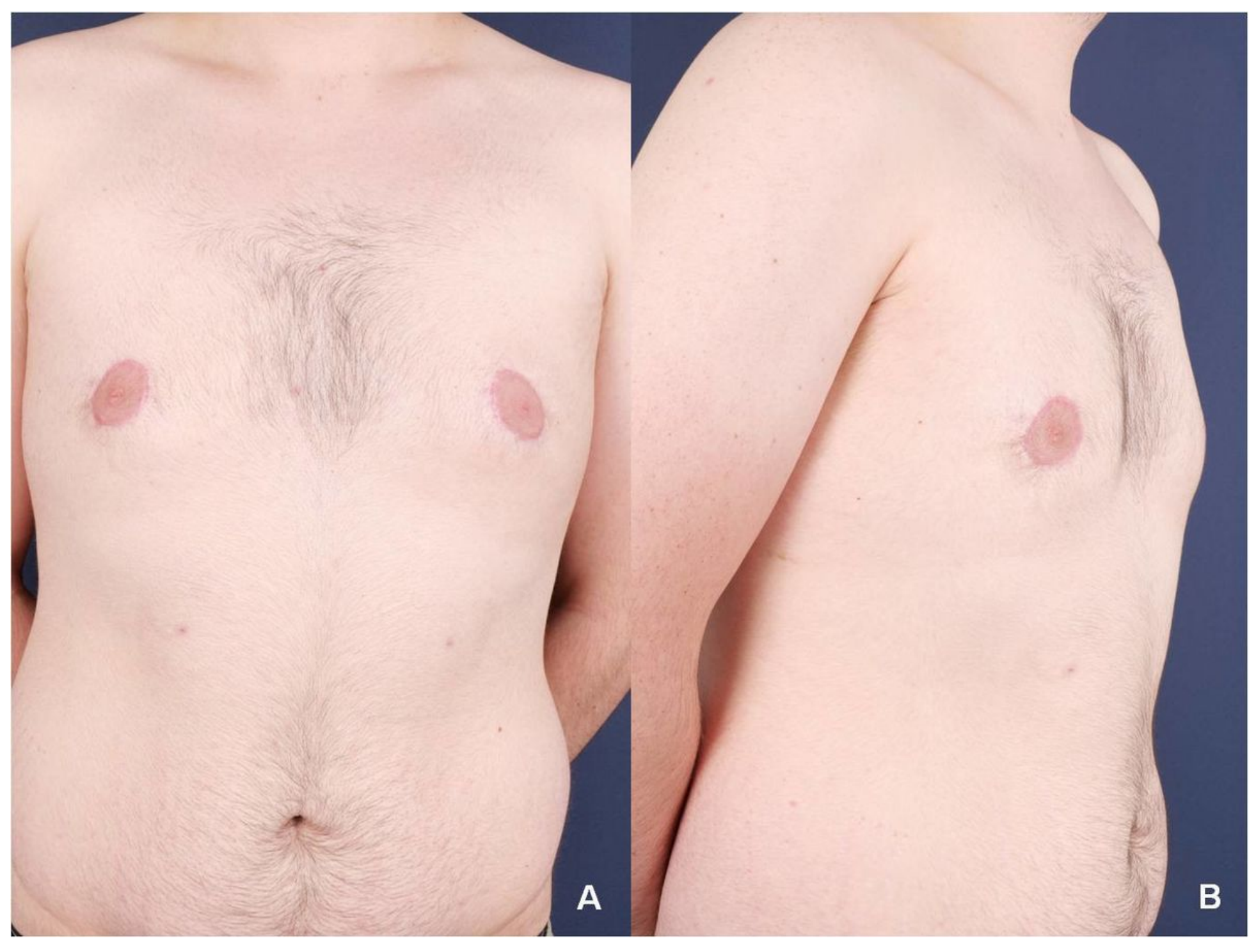

Figure 3

( $a$ and b): Postoperative result at 10-week follow-up after the hematoma evacuation.

\section{Supplementary Files}

This is a list of supplementary files associated with this preprint. Click to download.

- Table1.docx

- Table2.docx 